\title{
Remedial Amendment Delivery Near the Water Table Using Shear Thinning Fluids: Experiments and Numerical Simulations
}

\author{
M. Oostrom • M. J. Truex • V. R. Vermeul • L. Zhong • G. D. Tartakovsky • \\ T. W. Wietsma
}

Received: 12 June 2014 / Accepted: 19 August 2014 / Published online: 3 September 2014

(C) Springer International Publishing Switzerland 2014

\begin{abstract}
The use of non-Newtonian shear thinning fluids (STFs) containing xanthan is a potential enhancement for emplacing a solute amendment near the water table and within the capillary fringe. Most research to date related to STF behavior has involved saturated and confined conditions. A series of flow cell experiments were conducted to investigate STF emplacement in variable saturated homogeneous and layered heterogeneous systems. Besides flow visualization using dyes, amendment concentrations and pressure data were obtained at several locations. The experiments showed that injection of STFs considerably improved the subsurface distribution near the water table by mitigating preferential flow through higher permeability zones compared to no-polymer injections. The phosphate amendment migrated with the xanthan STF without retardation. Despite the high viscosity of the STF, no excessive mounding or preferential flow were observed in the unsaturated zone. The STOMP simulator was able to predict the experimentally observed fluid displacement and amendment concentrations well. Based on the observed pressure gradients and concentration data in layers of differing hydraulic conductivity, cross flow between layers was identified as the main mechanism transporting STFs into lower permeability layers.
\end{abstract}

Keywords Shear thinning fluids $\cdot$ Intermediate-scale experiments $\cdot$ Remedial amendment

\section{Introduction}

Injection of remediation amendments to a targeted subsurface treatment zone must consider enabling sufficient residence time for the desired reactions to occur. For example, laboratory studies of phosphate solution emplacement in uranium-contaminated sediments at the Hanford

M. Oostrom $(\bowtie) \cdot$ M. J. Truex $\cdot$ V. R. Vermeul $\cdot$ L. Zhong $\cdot$ G. D. Tartakovsky

Energy and Environment Directorate, Pacific Northwest National Laboratory, P.O. Box 999, Richland, WA 99354, USA

e-mail: mart.oostrom@pnnl.gov

T. W. Wietsma

Environmental Molecular Sciences Laboratory, Pacific Northwest National Laboratory, P.O. Box 999, Richland, WA 99354, USA 
Site in Washington has been shown to effectively reduce leaching of uranium by the sequence of the following mechanisms: a) precipitation of one or more calcium-phosphate precipitates, b) adsorption of calcium-uranium-carbonate aqueous species onto the phosphate precipitate, and c) formation of autunite or apatite, which are low solubility uranyl-phosphate precipitates (Wellman et al. 2008; Shi et al. 2009). A near-water table injection of a phosphate solution at the Hanford Site resulted in the formation of some calcium-phosphate precipitate and uranium groundwater concentration decreased for a short period after the injection before concentrations rebounded to higher levels again (Vermeul et al. 2009). One of the reasons the phosphate injection did not result in an effective long-term solution was that high groundwater velocities caused considerable advective transport and dispersion of the injected amendment. These conditions were unfavorable for sufficient formation of calcium- and uranyl-phosphate minerals within the targeted treatment zone. So, while the concept of using phosphate to emplace long-term treatment capacity within the aquifer had been shown in the laboratory, its use for direct treatment of uranium in the field was limited by ineffective delivery, primarily related to insufficient residence time of the reactive amendments in the targeted treatment zone.

To overcome the negative effects of high groundwater velocities on amendment emplacement near the water table, injection using a non-Newtonian shear thinning fluid (STF) was investigated. The viscosity of a STF decreases as a function of the shear rate applied to the fluid. In porous media, shear rates of injected fluids are a function of fluid velocity and hydraulic properties such as porosity and hydraulic conductivity (Martel et al. 1998). Due to high velocities near the injection well, shear rates are relatively high and STFs help maintain lower injection pressures than would occur with injection of a non-STF of the same static viscosity (Silva et al. 2012; Truex et al. 2011, 2014). After injection, the viscosity increases and the solution may remain hydraulically stable (i.e., groundwater will flow around a shearthinning polymer zone) until the polymer degrades. Laboratory examples of relatively stable polymer solutions in moving groundwater have been described by Zhong et al. (2011).

Besides potentially creating hydraulically stable zones where amendments have an opportunity to enhance remediation, an additional benefit of using STFs is that amendments may be forced into low permeability zones, potentially containing a higher mass of contaminant. Contaminants residing in such zones have the potential to cause persistence of plumes and increase the remediation timeframe because of diffusion-controlled release of contaminants back into transmissive zones (i.e., matrix or back diffusion). The potential impact of this diffusive process has been well documented in the literature (e.g., Chapman and Parker 2005). Injection of a viscous fluid into a heterogeneous subsurface induces cross-flow between higher- and lower-permeability layers, as described in detail by Silva et al. (2012). In this process, mobility reduction behind the viscous injection fluid front in a higher-permeability layer creates a transverse pressure gradient that drives viscous fluids into adjacent less permeable layers. The mobility reduction in the higher-permeability layer is further enhanced by water movement from the lower- to higher-permeability layer ahead of the viscous injection fluid front in response to the upstream cross-flow process.

Although alternative polymers such as guar gum (Tiraferri et al. 2008; Tiraferri and Sethi 2009) and Slurry Pro ${ }^{\mathrm{TM}}$ (Oostrom et al. 2007; Truex et al. 2011) have been used for subsurface applications, the most widely investigated STFs for remediation purposes contain the biopolymer xanthan. These solutions show strong shear-thinning behavior over a range of polymer concentrations and salinities, and when mixed with a variety of remedial amendments (Zhong et al. 2013). In the laboratory, xanthan-containing STFs have been used to enhance the delivery of particulate suspensions (Comba and Sethi 2009; Comba et al. 2011; Vecchia et al. 2009; Xue and Sethi 2012) and remedial amendment emplacement into low-permeability zones in laboratory 2-D flow cell heterogeneous systems (Chokejaroenrat et al. 2013, 2014; Martel 
et al. 1998; Robert et al. 2006; Smith et al. 2008; Silva et al. 2012; Zhong et al. 2008, 2011). In addition, several numerical models have been developed to simulate xanthan emplacement and distribution in heterogeneous systems (e.g., Chokejaroenrat et al. 2013; Silva et al. 2013; Tosco and Sethi 2010; Zhong et al. 2008). The models presented by Zhong et al. (2008) and Chokejaroenrat et al. (2013) use a simple power function to describe the STF rheology, whereas the Silva et al. (2013) approach uses the more elaborate Meters' equation (Meter and Bird 1964), and Tosco and Sethi (2010) use the Cross model (Cross 1965) to account for both xanthan and iron particle concentrations. The Chokejaroenrat et al. (2013) model allows for inclusion of the amendment effects on shear thinning and uses the Brinkman (Brinkman 1949) equation for explicit viscosity computations. Silva et al. (2013) use a modified UTCHEM (Delshad et al. 1996), considering the effects of mechanical filtration, potential permeability reduction, and xanthan sorption. The relatively successful laboratory experiments and advances in numerical development have led to recent field applications. For instance, Truex et al. (2014) examine the use of a xanthan STF to improve the uniformity of remedial amendment distribution for in situ treatment of contaminants within a heterogeneous aquifer at Joint Base Lewis McChord in Washington State.

Although there has been considerable progress in the understanding of STF subsurface behavior, the vast majority of the research so far has been completed with an emphasis on saturated, confined systems, using visualization with dyes as the main mode of identifying flow and transport. To our knowledge, STF behavior in variably saturated systems, i.e., the conditions for potential near-water table xanthan STF emplacement of remedial amendments, has not been investigated. In this work, a series of five flow cell experiments was conducted where xanthan STFs were injected near the water table in homogeneous and layered heterogeneous configurations. Besides flow visualization, amendment concentration and fluid pressure data were obtained to study emplacement of the STF. The main objectives of the study were to (1) investigate the potential of enhanced remedial-amendment delivery with STF for near-water table emplacement, and (2) test and verify the STOMP simulator (White and Oostrom 2006) for xanthan polymer shear-thinning behavior in variably saturated systems.

\section{Materials and Methods}

\subsection{Flow Cell Experiments}

Five experiments were conducted in a 0.5-m-long, 0.4-m-high, and 0.051-m-wide flow cell. The front and back for the two-dimensional (2D) flow cell consisted of polycarbonate plastic and the frame was made out of stainless steel. Additional flow cell details can be found in Zhong et al. (2008). Schematics of the flow cell packing configurations and the approximate water table location for each experiment are presented in Fig. 1. In Exp. I, the flow cell was homogeneously packed with 12/20 mesh Accusand (Unimin Corporation, Le Sueur, MN). In the other four experiments, different configurations of 12/20 and 40/50 mesh Accusand were used.

The measured hydraulic properties of the two sands are listed in Table 1. The hydraulic conductivity was obtained using a constant head method described by Wietsma et al. (2009). The retention parameters were obtained by fitting the van Genuchten (1980) saturationpressure head equation to saturation data obtained using a dual-energy gamma system (Oostrom et al. 1998), after draining an initially saturated 1-m-long column. The average porosity and dry bulk density values listed in Table 1 were obtained gravimetrically. For additional information on the Accusands, the reader is referred to Schroth et al. (1996). The 

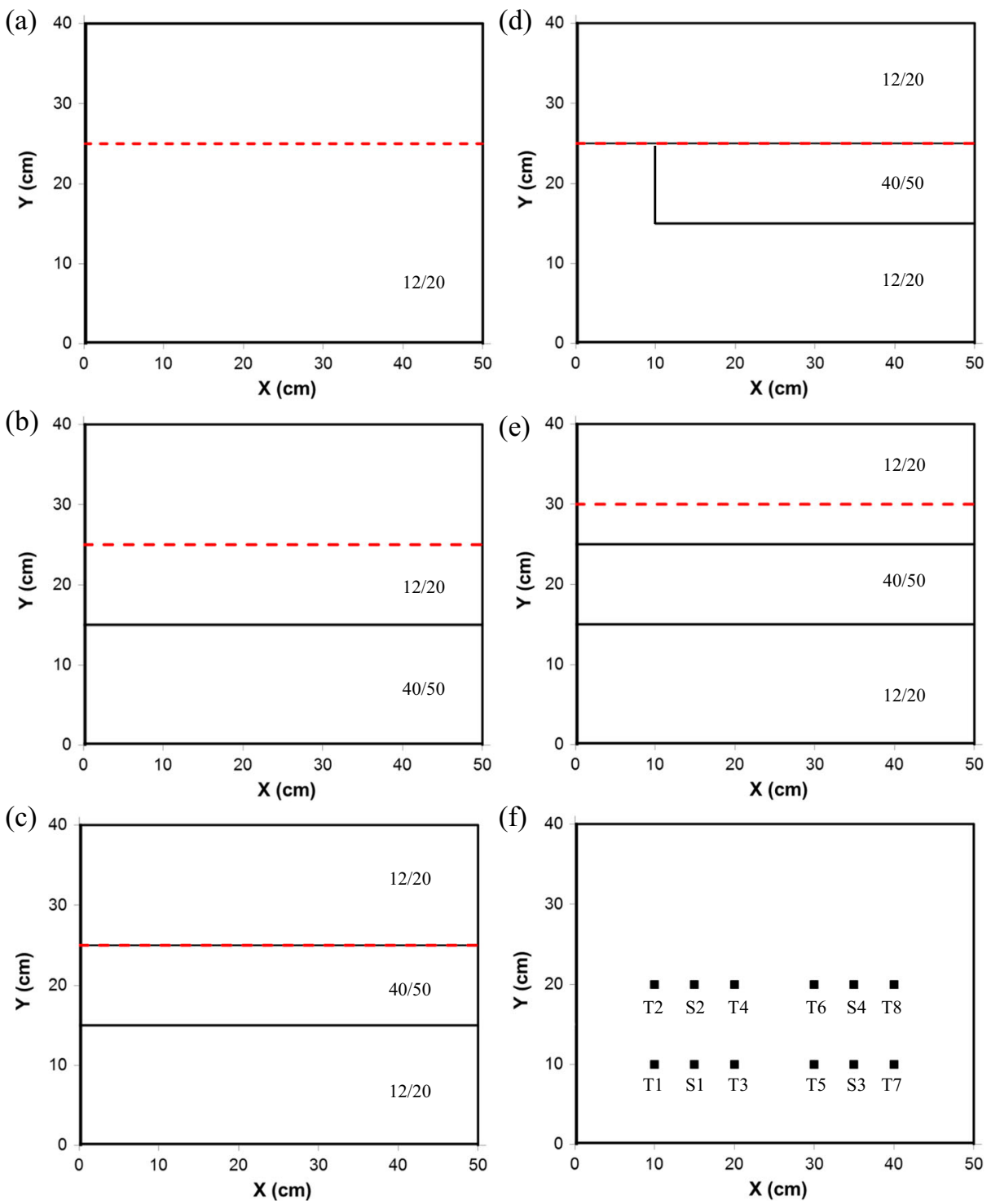

Fig. 1 Configurations of Experiment (a) I, (b) II, (c) III, (d) IV, and (e) V. The locations of the sampling ports (S1-S4) and tensiometers (T1-T8) are shown in (f). The position of the water table is indicated with a red dashed line. Fluids are injected between $y=15 \mathrm{~cm}$ and $y=25 \mathrm{~cm}$ at the left hand side

flow cell was packed under saturated conditions to avoid the formation of entrapped air. After completion of a packing, the water table was lowered from the top of the flow cell to the locations shown in Fig. 1 at a rate of $1.67 \times 10^{-4} \mathrm{~m} / \mathrm{s}(1 \mathrm{~cm} / \mathrm{min})$. The experiments were started after water drainage had ceased.

The experiments consisted of two parts, each lasting 2 h. In the first part (e.g., Exp. Ia), a tracer flood consisting of $75 \mathrm{ppm}$ Amaranth (red) dye was injected. For the first $30 \mathrm{~min}$ of this flood, a 25 ppm bromide pulse was included. In the second part (e.g., Exp. Ib), a polymer flood 
Table 1 Hydraulic properties of 12/20 and 40/50 mesh Accusand

\begin{tabular}{lllllll}
\hline Sand & $\begin{array}{l}\text { van Genuchten } \\
\alpha(1 / \mathrm{m})\end{array}$ & $\begin{array}{l}\text { van } \\
\text { Genuchten } n\end{array}$ & $\begin{array}{l}\text { Residual Saturation } \\
\left(\mathrm{m}_{\text {liquid }}^{3} / \mathrm{m}_{\text {pore space }}^{3}\right)\end{array}$ & $\begin{array}{l}\text { Hydraulic Cond., } \\
K_{\text {sat }}(\mathrm{m} / \mathrm{s})\end{array}$ & $\begin{array}{l}\text { Porosity } \\
(-)\end{array}$ & $\begin{array}{l}\text { Particle Size, } \\
d_{50}(\mathrm{~m})^{\mathrm{a}}\end{array}$ \\
\hline $12 / 20$ & 16.32 & 5.16 & 0.042 & $4.73 \times 10^{-3}$ & 0.348 & $1.11 \times 10^{-3}$ \\
$40 / 50$ & 4.81 & 4.63 & 0.058 & $7.04 \times 10^{-4}$ & 0.345 & $3.59 \times 10^{-4}$ \\
\hline
\end{tabular}

${ }^{\text {a }}$ Schroth et al. (1996)

consisting of 600 ppm xanthan, 400 ppm NaCl, and 75 ppm Brilliant Blue FCF was injected. For the first $30 \mathrm{~min}$ of the polymer flood, a $200 \mathrm{ppm}$ phosphate amendment (in the form of $\mathrm{NaH}_{2} \mathrm{PO}_{4}$ ) was added as an example of a solute remedial amendment. The dyes were added to color the displacing fluids, allowing for visual observations. The polymer flood immediately followed the tracer flood, resulting in a $4 \mathrm{~h}$ total experiment time. The dyes, phosphate, and bromide were obtained from Aldrich Chemical Company (Milwaukee, WI) and xanthan gum was purchased from the Kelco Oil Field Group (Houston, TX). The apparent viscosity - shear rate relation of the $600 \mathrm{ppm}$ xanthan polymer, amended with $200 \mathrm{ppm} \mathrm{NaH} \mathrm{NO}_{4}$ and $400 \mathrm{ppm}$ $\mathrm{NaCl}$, is shown in Fig. 2. The rheological properties were obtained using a Physica 101 rheometer (Anton Paar USA Inc., Ashland, VA) with a CC27-SS measuring unit.

In all experiments, fluids were injected at two inflow ports with a rate of $12.5 \mathrm{~mL} / \mathrm{min}$ each, for a total combined rate of $25 \mathrm{~mL} / \mathrm{min}$, using Encynova (Broomfield, $\mathrm{CO}$ ) high-precision piston pumps. Denoting the left-bottom corner of the flow cell as $(x \mathrm{~cm}, y \mathrm{~cm})=(0,0)$, the inflow ports were located at $(0,17.5)$ and $(0,22.5)$. The ports were connected to 5 -cm-high redistribution areas, recessed at the porous medium side of the left vertical member of the frame, resulting in uniform fluid injection from $y=15$ to $25 \mathrm{~cm}$. Outflow occurred through eight equally-spaced effluent ports, connected to a constant-head chamber where the water level was kept at $y=25 \mathrm{~cm}$ for Exp. I through IV, and at $y=30 \mathrm{~cm}$ for Exp. V.

The locations of eight tensiometers (T1-T8) and four sampling ports (S1-S4) are shown in Fig. 1f. Fluid pressures were measured with Heise DXD4540 transducers (Ashcroft Inc.,

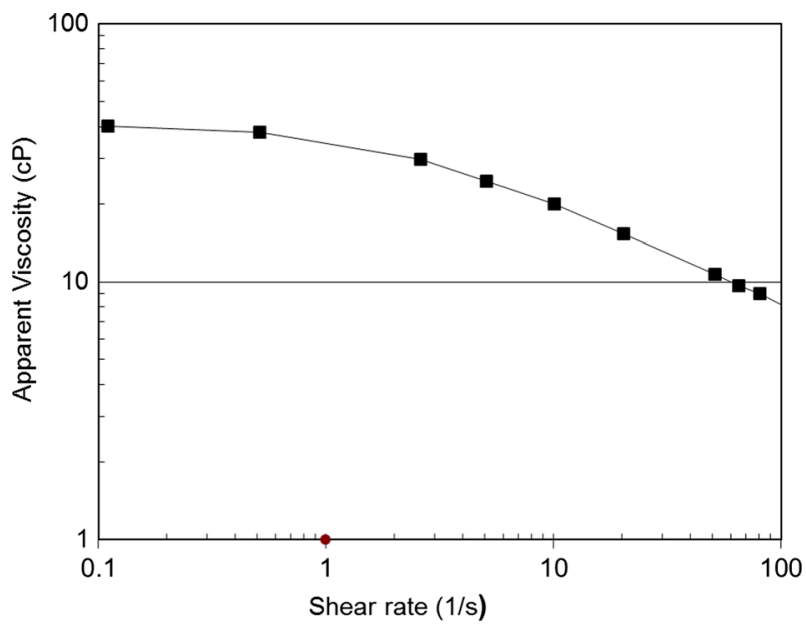

Fig. 2 Measured apparent viscosity as a function of shear rate for the $600 \mathrm{ppm}$ xanthan polymer solution with 200 ppm $\mathrm{NaH}_{2} \mathrm{PO}_{4}$ and 400 ppm $\mathrm{NaCl}$ 
Stratford, CT), which have an accuracy of $0.02 \%$ and a range of $\sim 350 \mathrm{~cm}$ of water pressure. Liquid samples $(1 \mathrm{~mL})$ were taken approximately every $10 \mathrm{~min}$ at each of the four locations using gas-tight syringes. Phosphate and bromide concentrations were obtained using ion chromatography.

\subsection{Numerical Simulations}

The water operational mode of the STOMP (Subsurface Transport Over Multiple Phases) simulator (White and Oostrom 2006) with sequential electrolyte and solute transport was used to model the experiments. The applicable governing equations are the component conservation equations for water flow, electrolyte (xanthan) transport, and solute (bromide and phosphate) transport in the aqueous phase (Oostrom et al. 2001; Schroth et al. 2001). In this STOMP mode, xanthan is considered to be an electrolyte as it affects fluid viscosity. The xanthan massconservation equation is solved after convergence of the water conservation equation, using an operator splitting approach. Bromide and phosphate are considered to be solutes because fluid properties are not affected at the concentrations used in the reported experiments. The water and solute conservation equations are solved sequentially. The partial differential equations for flow and transport are discretized following the integrated-volume finite difference method by integrating over a control volume (Patankar 1980). The $50 \times 40 \mathrm{~cm}$ computational domain was discretized into 8,000 uniform $(0.5 \mathrm{~cm} \times 0.5 \mathrm{~cm})$ grid blocks. Additional refinements did not change the simulation results. Using Euler backward time differencing, yielding a fully implicit scheme, a series of nonlinear algebraic expressions is derived for the water flow equation. The algebraic forms of the nonlinear governing equations are solved with a multivariable, residual-based Newton-Raphson iterative technique where the Jacobian coefficient matrix is composed of the partial derivatives or the governing equations with respect to the primary variables. The algebraic expressions are evaluated using upwind interfacial averaging to fluid density and mass fractions. For the simulations described in this contribution, harmonic averages were used for all other flux components. The maximum number of Newton-Rhapson iterations was eight, with a convergence factor of 10-6. An implicit totalvariation diminishing (TVD) technique was used to minimize artificial diffusion, preserving sharp displacement fronts while avoiding oscillations that commonly affect classical higherorder schemes. To ensure that the Courant number criterion was not exceeded, the maximum allowable time step was $10 \mathrm{~s}$. A longitudinal dispersivity value of $0.4 \mathrm{~cm}$ was used for both sands, experimentally obtained by Silva et al. (2012) for similar Unimin sands. A value of $0.04 \mathrm{~cm}$ was assigned to the transverse dispersivity. To simulate unsaturated flow, the van Genuchten (1980) retention properties listed in Table 1 were used in with the Mualem (1976) relative permeability-saturation relation.

Polymer fluid viscosity was computed as a function of shear rate and polymer concentration (Eq. 1), following a method outlined by Lopez et al. (2003) where the effective viscosity, $\mu_{\text {eff }}$ $(\mathrm{Pa} \mathrm{s})$, is a constant for the Newtonian ranges at low $\left(<0.1 \mathrm{~s}^{-1}\right)$ and high $\left(>100 \mathrm{~s}^{-1}\right)$ shear rates, but follows a power-law model for the range where shear-thinning occurs:

$$
\mu_{\text {eff }}=\max \left[\mu_{\infty} ; \min \left\{\left(a \frac{C}{C_{o}}\right) \gamma^{b} ; \mu_{0}\right\}\right]
$$

where $\mu_{\infty}$ and $\mu_{0}\left(\mathrm{~kg} \mathrm{~m}^{-1} \mathrm{~s}^{-1}\right)$ are the fluid viscosity at high and low shear rates, respectively; $C / C_{o}$ is the normalized polymer concentration; $a\left(\mathrm{~kg} \mathrm{~m}^{-1} \mathrm{~s}^{-1}\right)$ and $b$ are powerlaw model constants, obtaining by fitting to the experimental data. The obtained $a, b, \mu_{0}$, and $\mu_{\infty}$ values for the $600 \mathrm{ppm}$ xanthan polymer solution in Fig. 2 are $2.7 .8 \times 10^{-3} \mathrm{~kg} \mathrm{~m}^{-1} \mathrm{~s}^{-1}$, 
$-0.19 \times 10^{-3}, 1.002 \times 10^{-3} \mathrm{~kg} \mathrm{~m}^{-1} \mathrm{~s}^{-1}$, and $4.4 \times 10^{-2} \mathrm{~kg} \mathrm{~m}^{-1} \mathrm{~s}^{-1}$, respectively. The shear rate $\gamma$ $(1 / \mathrm{s})$ in Eq. (1) is computed as

$$
\gamma=\frac{\alpha q}{\sqrt{k n}}
$$

where $\alpha$ is a shape parameter constant, $q$ is the Darcy velocity $(\mathrm{m} / \mathrm{s}), k$ is the permeability $\left(\mathrm{m}^{2}\right)$, and $n$ the porosity. For the simulations reported in this paper, a $\alpha$ value of 2.4 is used, recommended by Martel et al. (1998) for sands having similar diameters. Zhong et al. (2008) and Chokejaroenrat et al. (2013) have used the same value to successfully simulate xanthan transport in flow cells packed with similar sands.

\section{Results and Discussion}

In Exp. I, the tracer and polymer flood were conducted in a homogeneously packed flow cell containing medium-grained sand (12/20 mesh). The packing at the start of the tracer flood is shown in Fig. 3a, indicating the capillary fringe was approximately $5 \mathrm{~cm}$. This value is consistent with the value of $5.4 \mathrm{~cm}$ reported in Schroth et al. (1996). The red dye distributions for the tracer flood (Exp. Ia) after 0.5 and $1 \mathrm{~h}$ of injection are shown in Fig. $3 \mathrm{~b}$ and c, respectively. The simulated $\mathrm{C} / \mathrm{Co}=0.5$ dye contours are presented in Fig. $3 \mathrm{~d}$. The blue dye distributions for the polymer flood (Exp. Ib) after 0.5 and $1 \mathrm{~h}$ of injection are shown in Figs. $3 \mathrm{e}$ and $\mathrm{f}$ respectively. The simulated $\mathrm{C} / \mathrm{Co}=0.5$ blue dye contours are presented in Fig. $3 \mathrm{~g}$. To allow for comparisons of all the observations and simulation results, the same sequence of the visualization results is presented for all five experiments (see Figs. 5, 10, 13, and 15 for Exp. II, III, IV, and V, respectively) The maximum time of $1.0 \mathrm{~h}$ used in these figures is limited by the fastest moving dye in all the experiments, which occurred during Exp. IIa (Fig. 5c). Note that the red dye in the polymer flood pictures (Fig. 3e and f) are the remnants of the dye injected during the tracer flood experiment because the polymer flood immediately followed the tracer flood.

The plots in Fig. 3 show that the differences between tracer and polymer flooding are relatively small. For the polymer flood the front is steeper and the average height of the capillary fringe increased by approximately $1.5 \mathrm{~cm}$. The simulations of both floods (Fig. $3 \mathrm{~d}$ and g) show good agreement with the dye observations because both the increased plume steepness and capillary fringe are simulated properly. In Fig. 4, simulation and experimental results are presented for the bromide injection in the tracer flood and the phosphate amendment pulse in the polymer flood. Again, for comparison purposes, similar plots for the concentration data are presented for all experiments (see Figs. 6, 12, 14, and 16 for Exp. II, III, IV, and V, respectively). Consistent with Fig. 3, the plots in Fig. 4 demonstrate the limited effects of polymer flooding in this homogeneous configuration. Because of the location of the injection zone relative to the sampling ports, the arrival time at all locations slightly decreased for the polymer flood. For both bromide and the phosphate amendment, the agreement between simulations and experimental observations is good.

The rest of the experiments include layered heterogeneities and, for that reason, the results are more interesting. In Exp. II, as shown in Fig. 5, the tracer flood (Exp. Ila) rapidly moves through the 12/20-mesh sand to arrive at the outflow boundary just within $1 \mathrm{~h}$, with minimal red dye penetration into the 40/50-mesh sand. During the polymer flood (Exp. IIb), the mobility reduction in the $12 / 20$-mesh sand is obvious and considerably more blue dye enters the lower-permeability sand as a result of cross flow. This phenomenon is explained in more 


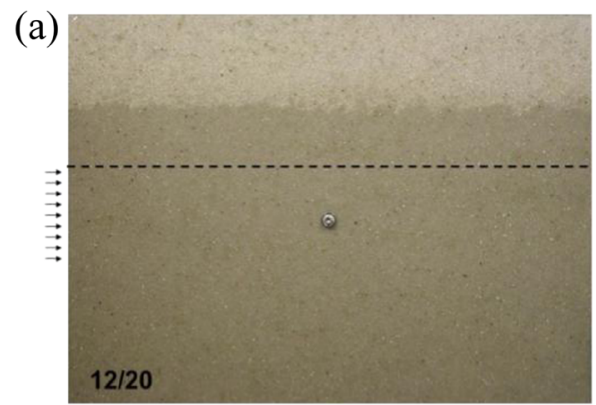

(b)

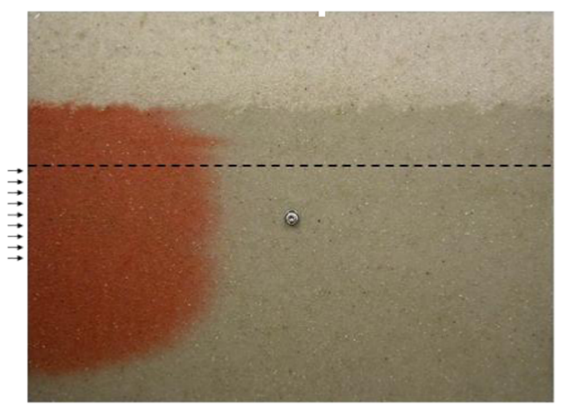

(c)

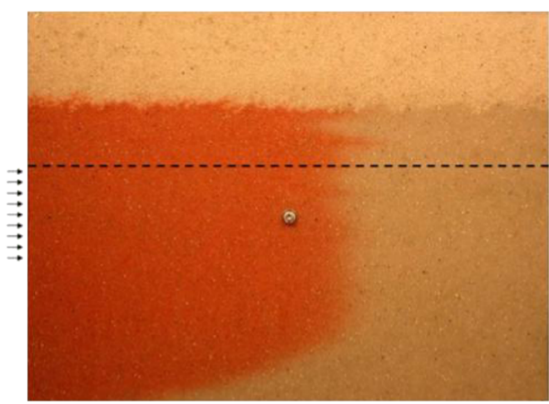

(d)

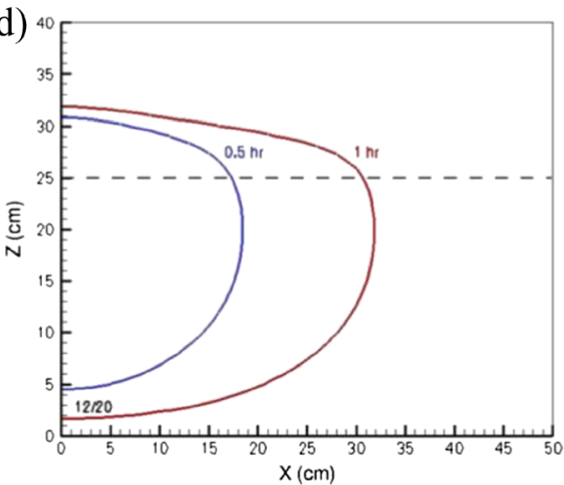

(e)

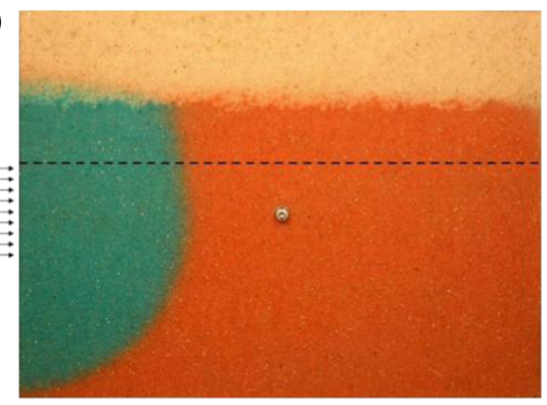

(f)

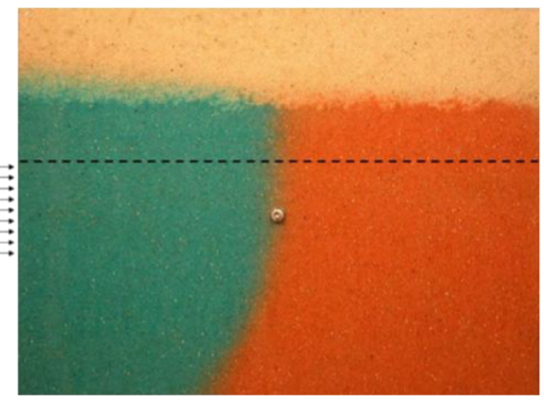

(g)

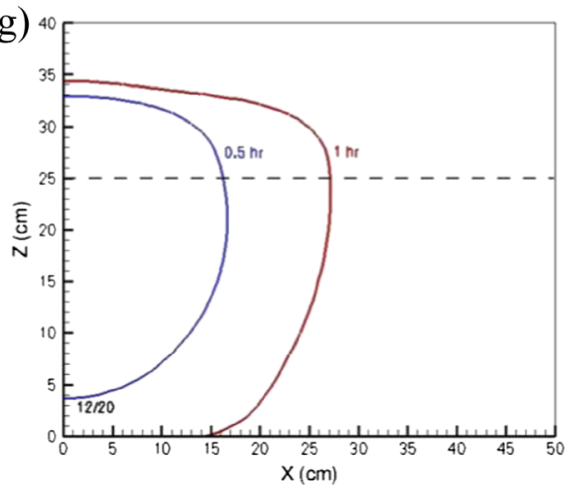

Fig. 3 Experiment I: (a) configuration; tracer distribution at (b) $0.5 \mathrm{~h}$ and (c) $1 \mathrm{~h}$; (d) predicted tracer $\mathrm{C} / \mathrm{C}_{\mathrm{o}}=0.5$ contours at 0.5 (blue) and $1 \mathrm{~h}(\mathrm{red})$; xanthan distribution at (e) $0.5 \mathrm{~h}$ and (f) $1 \mathrm{~h}$; and (g) predicted xanthan $\mathrm{C} / \mathrm{C}_{\mathrm{o}}=$ 0.5 contours at 0.5 (blue) and $1 \mathrm{~h}($ red $)$

detail later in this section. Again, the STOMP simulations and visual observations are in good agreement for both floods. The bromide concentrations for Exp. IIa demonstrate the fast 

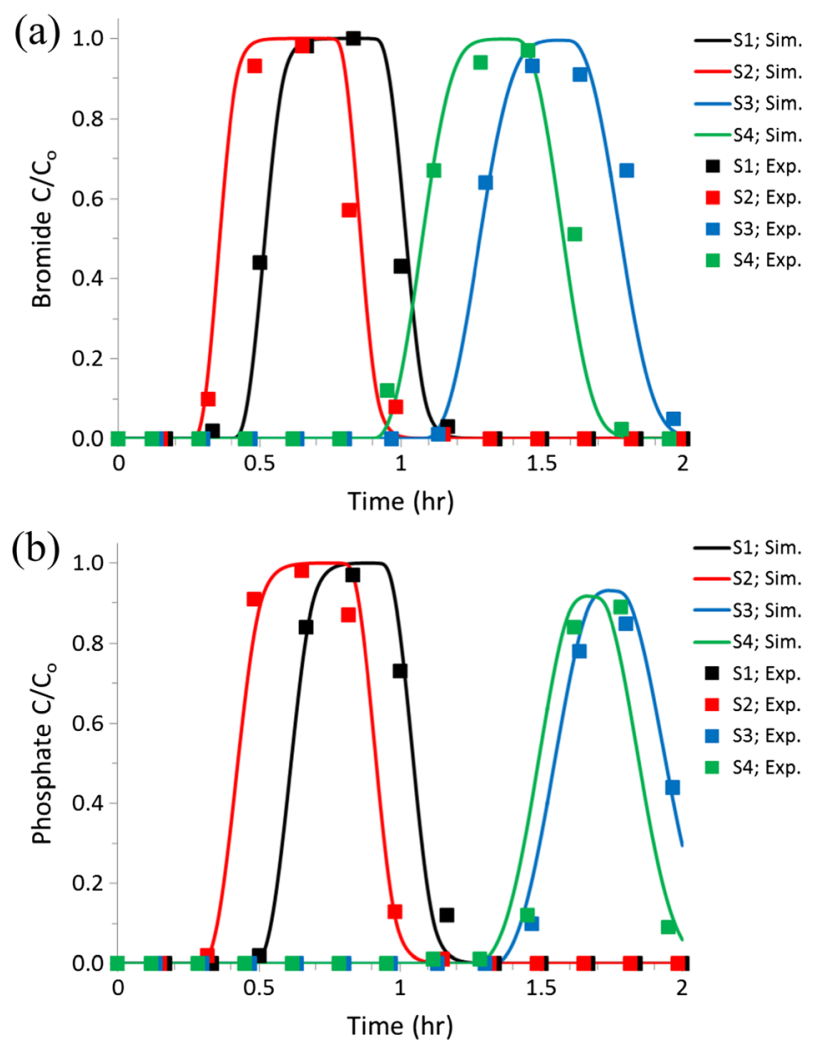

Fig. 4 Simulated and experimentally obtained (a) bromide concentrations for Exp. Ia, and (b) phosphate concentrations for Exp. Ib

breakthrough in the 12/20 sand, with relatively fast arrival times at sampling ports S2 and S4 (Fig. 6a). Consistent with the picture in Fig. 5, bromide started to arrive only during the latter phase of Exp. Ilb at port S1 in the lower permeability sand, but did not appear at port S3. As can be seen in Fig. 6b, the mobility reduction in the 12/20 sand due to the polymer viscosity is demonstrated by the delayed arrival time of phosphate at port S4, where the maximum concentration is reached almost $40 \mathrm{~min}$ later than during the tracer flood. In contrast, the amendment in the lower-permeability sand completely migrated past port S1 and even started to break through at port S3. It should be noted that due to the two-dimensional nature of the flow patterns in the flow cell, especially during the polymer flood, the areas under the respective breakthrough curves vary and are typically not equal to the applied pulse.

The pressure developments at the tensiometer locations show a linear increase after first arrival of the viscous STF (Fig. 7). The times when the pressures start the increase are consistent with the arrival times of the phosphate amendment (Fig. 6). Because the flow cell outflow level was kept constant at $y=25 \mathrm{~cm}$ (Fig. 1), the pressure increases did not result in considerable mounding in the unsaturated zone. Limited water mounding may also be expected in the field because the water table downstream of a STF flood should not be affected. This behavior can be seen in Fig. 7 where the pressures at downstream locations (T5 and T6) are not affected by polymer arrival at upstream locations ( $\mathrm{T} 1$ and $\mathrm{T} 2$ ). The figure also shows that the simulator is able to 
(a)

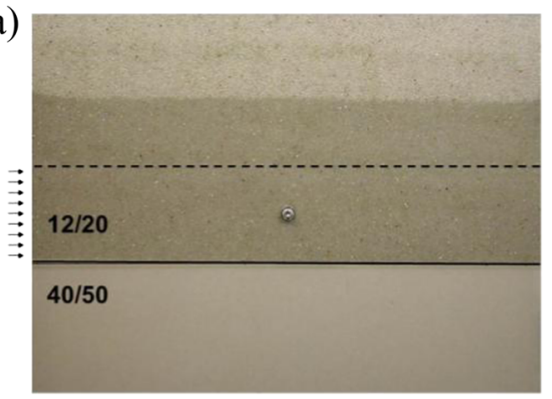

(b)

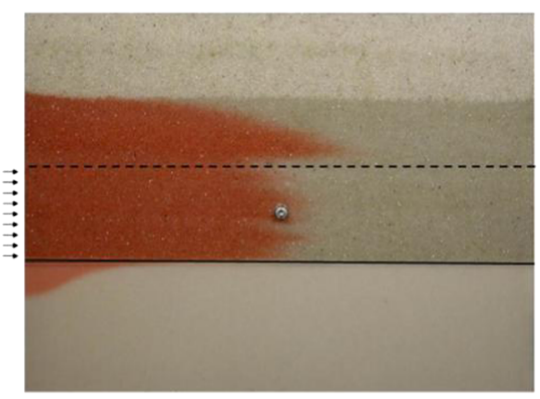

(c)

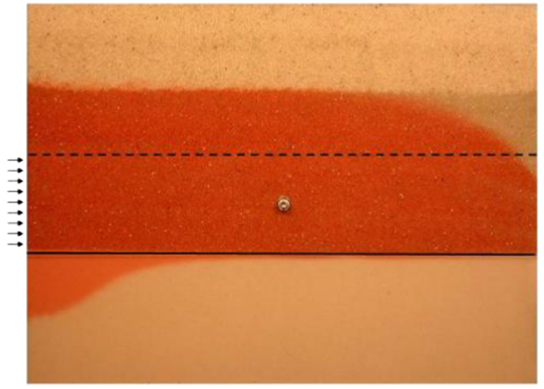

(d)

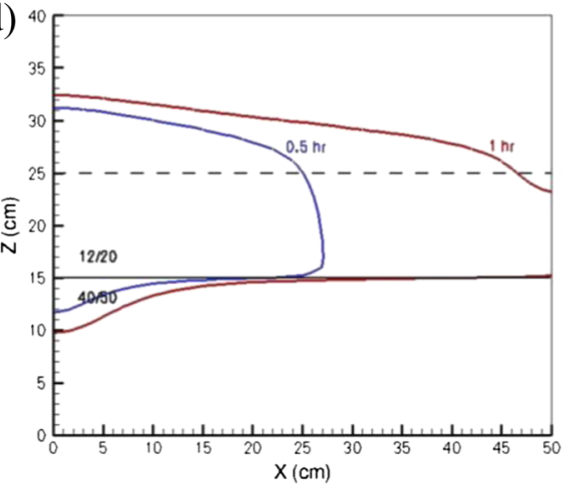

(e)

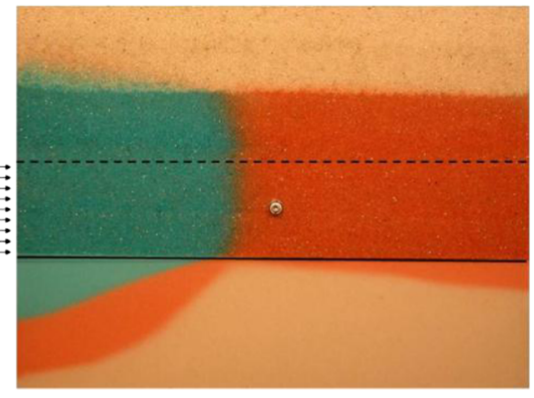

(f)

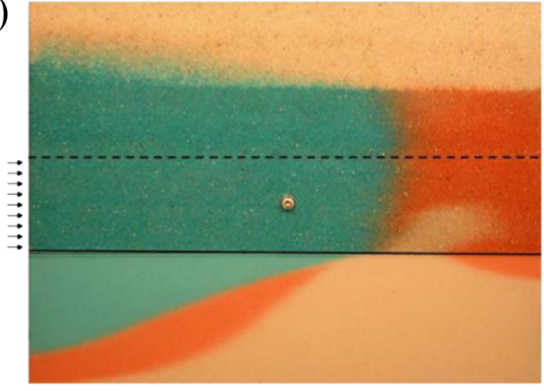

(g)

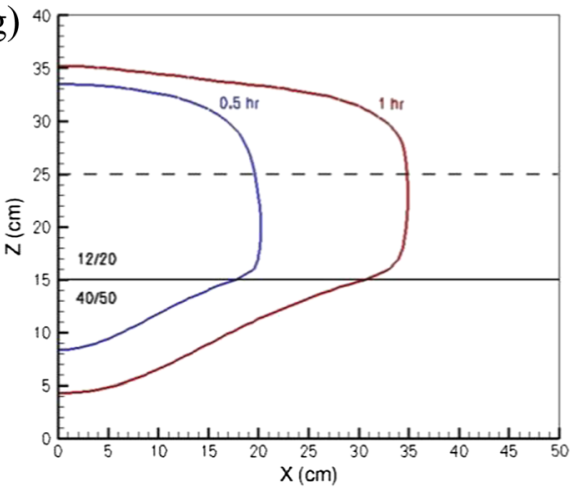

Fig. 5 Experiment II: (a) configuration; tracer distribution at (b) $0.5 \mathrm{~h}$ and (c) $1 \mathrm{~h}$; (d) predicted tracer $\mathrm{C} / \mathrm{C}_{\mathrm{o}}=0.5$ contours at 0.5 (blue) and $1 \mathrm{~h} \mathrm{(red)}$; xanthan distribution at (e) $0.5 \mathrm{~h}$ and (f) $1 \mathrm{~h}$; and (g) predicted xanthan $\mathrm{C} / \mathrm{C}_{\mathrm{o}}=$ 0.5 contours at 0.5 (blue) and $1 \mathrm{~h}(\mathrm{red})$

predict pressure changes associated with arrival of the polymer reasonably well, including the timing of initial pressure increase and the slopes of the lines. 

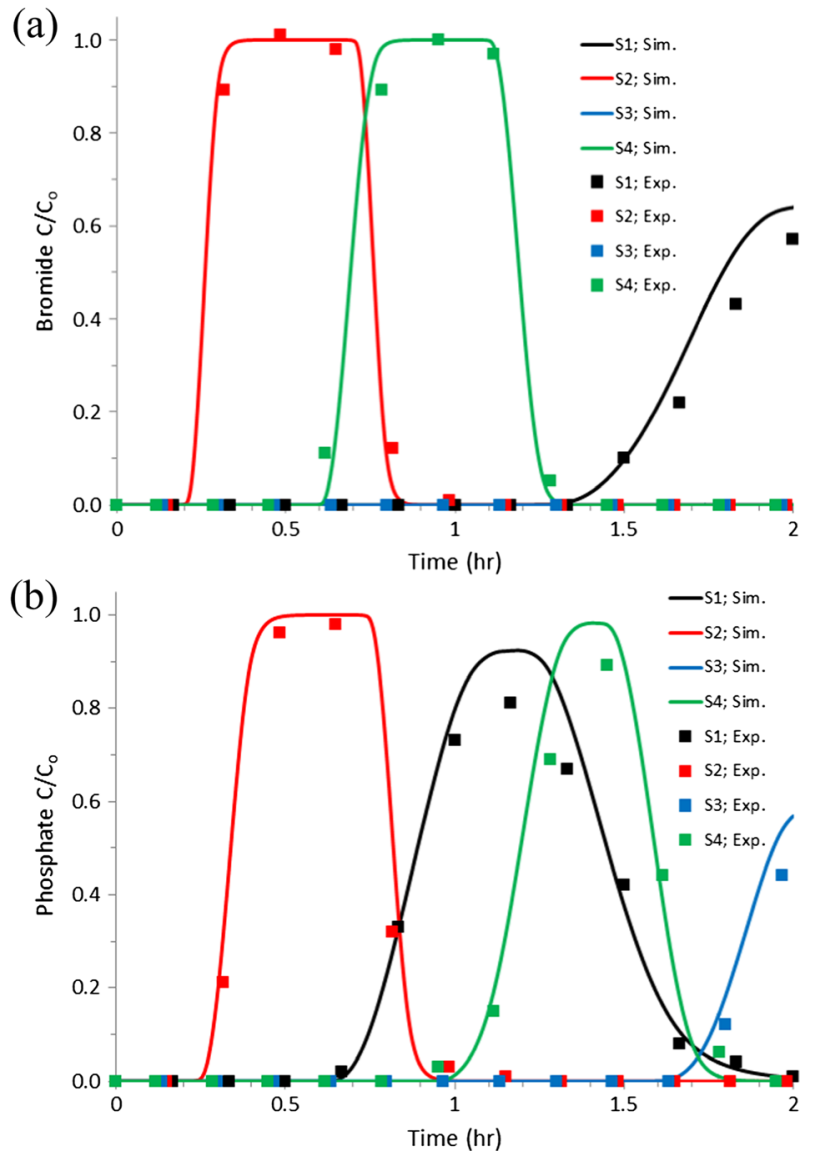

Fig. 6 Simulated and experimentally obtained (a) bromide concentrations for Exp. IIa, and (b) phosphate concentrations for Exp. IIb

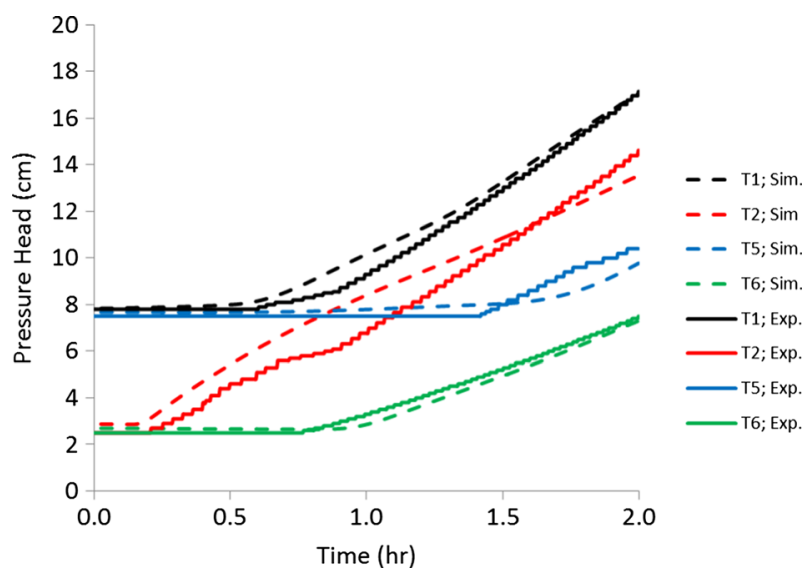

Fig. 7 Simulated and experimentally obtained pressure head values at tensiometer locations T1, T2, T5, and T6 for Exp. IIb 


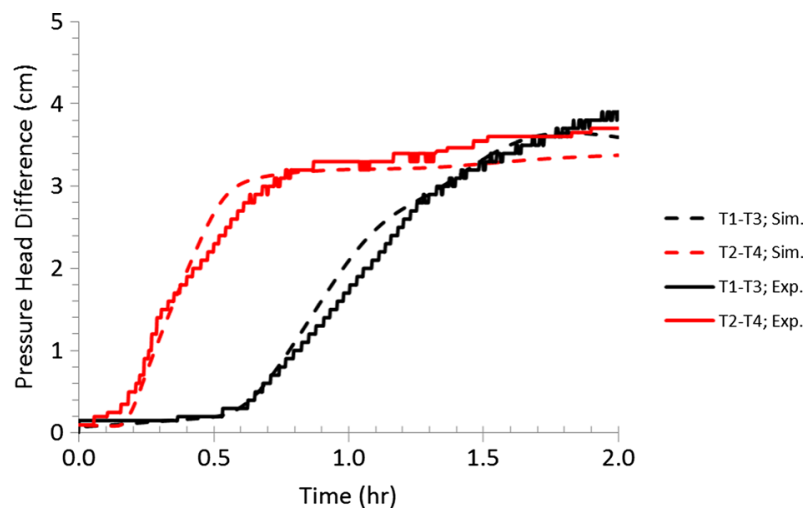

Fig. 8 Simulated and measured pressure head differences between T1-T3 and T2-T4 for Exp. IIb

The determination of pressure data allowed us to demonstrate the occurrence of the crossflow phenomenon forcing STF to move from higher to lower permeability zones. The process has been explained in considerable detail by, e.g., Silva et al. (2012) but supporting data have not been presented. In Fig. 8, pressure differences in the 12/20-mesh sand (T2 - T4) and the 40/50 mesh sand (T1 - T3) are presented for Exp. Ilb that show the development of pressure gradients as a function of time. In the higher permeability sand, the STF arrives first (red lines), leading to pressure gradients that are larger than in the 40/50-mesh sand (black lines). As a result, part of the polymer solution is forced to migrate downwards from the $12 / 20$-mesh into the 40/50-mesh sand. After arrival of the STF at the tensiometer locations, pressure differences and vertical fluid movement in the targeted zone diminish. Besides cross-flow from higher- to lower-permeability zones, the reverse process, i.e., flow from the 40/50-mesh into the 12 / 20 mesh sand, takes place ahead of the STF front in the 12/20-mesh. This cross-flow component, required to maintain fluid conservation in a layered system, can be seen in Fig. 5f, where clear water from the 40/50-mesh sand makes its way into the $12 / 20$-mesh sand just ahead of the blue STF. The clear water displaces the red dye that originally occupied the coarser sand. Cross-flow into the 12/20-mesh sand is also demonstrated in Fig. 9, where

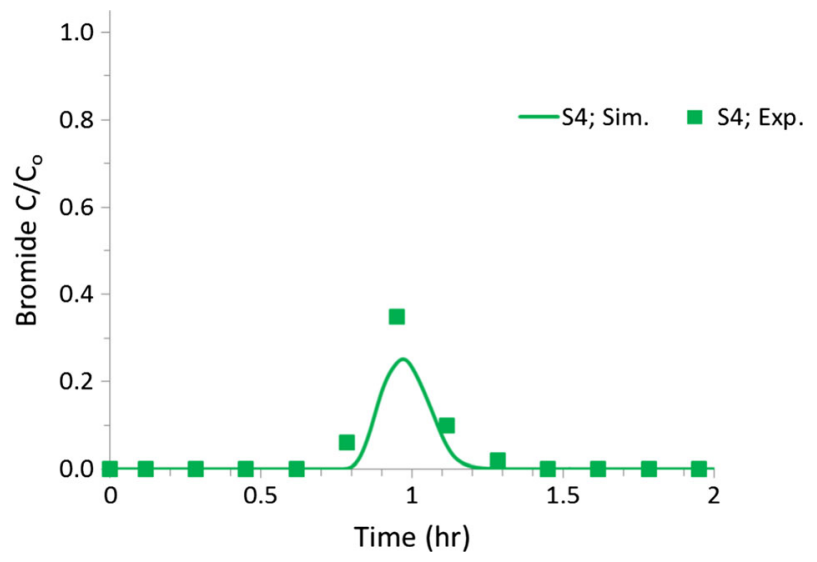

Fig. 9 Simulated and experimentally obtained bromide concentrations at sampling port S4 during Exp. IIIb. The appearance of bromide at this location is an indication of cross-flow into the $12 / 20$ sand from the $40 / 50$ sand below 


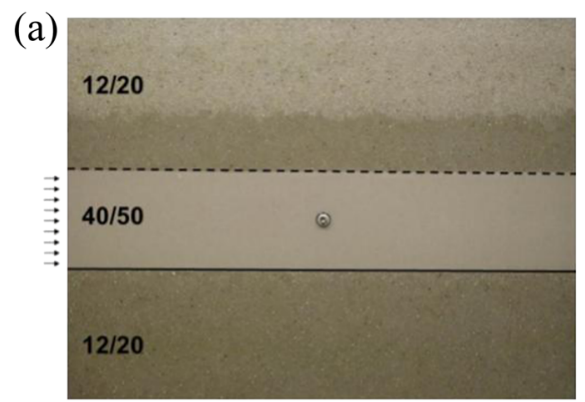

(b)

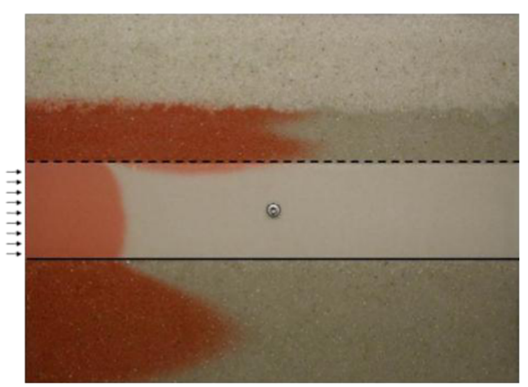

(c)

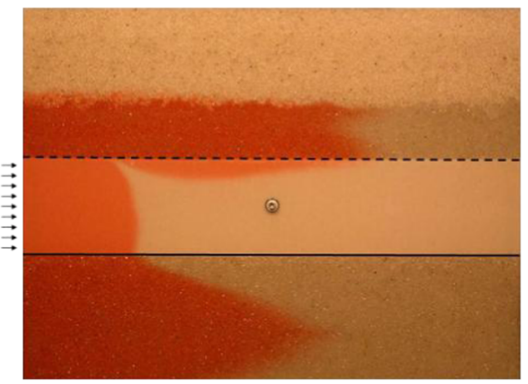

(d)

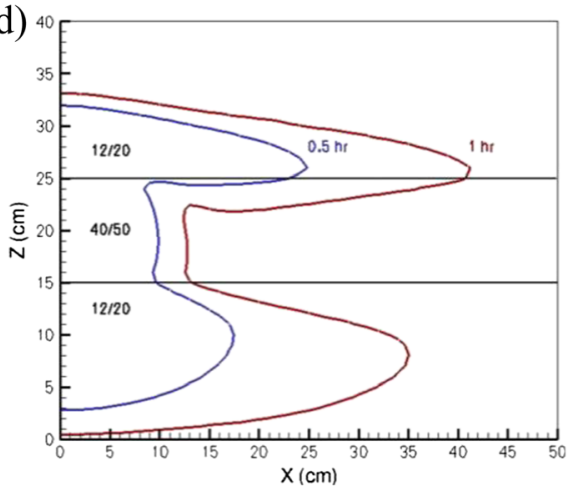

(e)

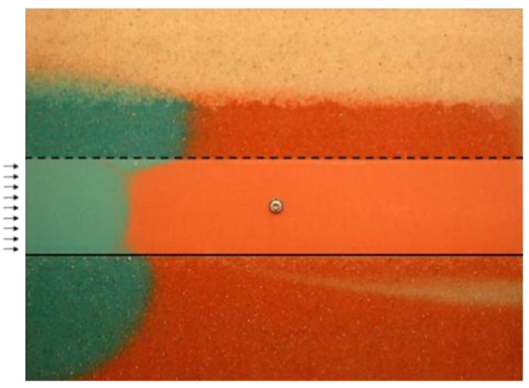

(f)

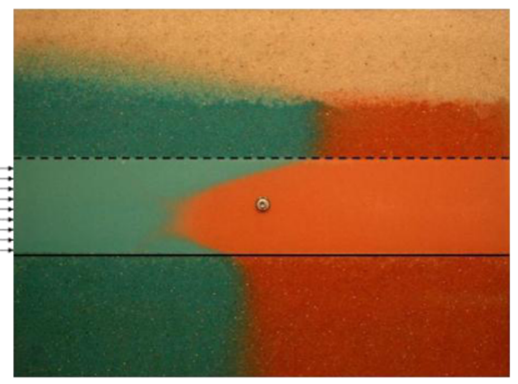

(g)

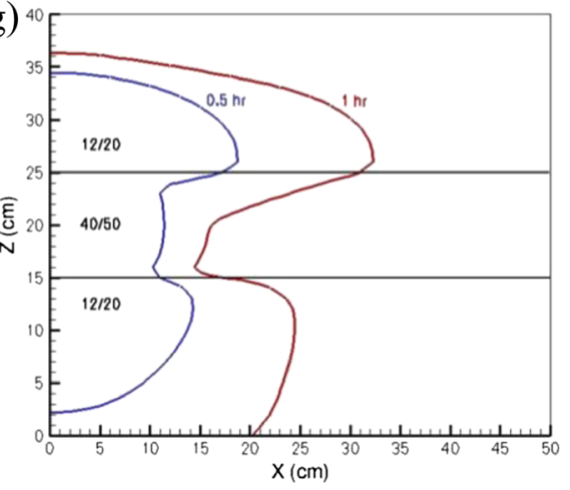

Fig. 10 Experiment III: (a) configuration; tracer distribution at (b) $0.5 \mathrm{~h}$ and (c) $1 \mathrm{~h}$; (d) predicted tracer $\mathrm{C} / \mathrm{C}_{\mathrm{o}}=$

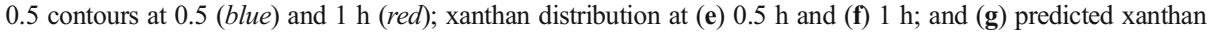
$\mathrm{C} / \mathrm{C}_{\mathrm{o}}=0.5$ contours at 0.5 (blue) and $1 \mathrm{~h}($ red $)$

bromide, pushed out of the 40/50 sand, arrives at sampling port S4 during the polymer flood. Bromide migrated past this location already during the tracer flood (Fig. 6b). The second 


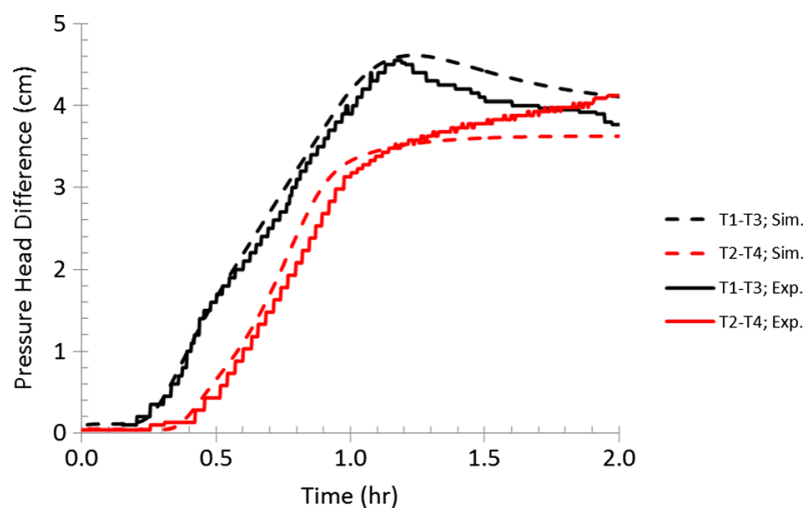

Fig. 11 Simulated and measured pressure head differences between T1-T3 and T2-T4 for Exp. IIIb

arrival represents the small amount of bromide that was forced into the 40/50-mesh sand during the tracer flood. Figures. 8 and 9 show how pressure and concentration data can be used to clearly demonstrate both components of cross-flow between two-layers with different permeability during STF application.

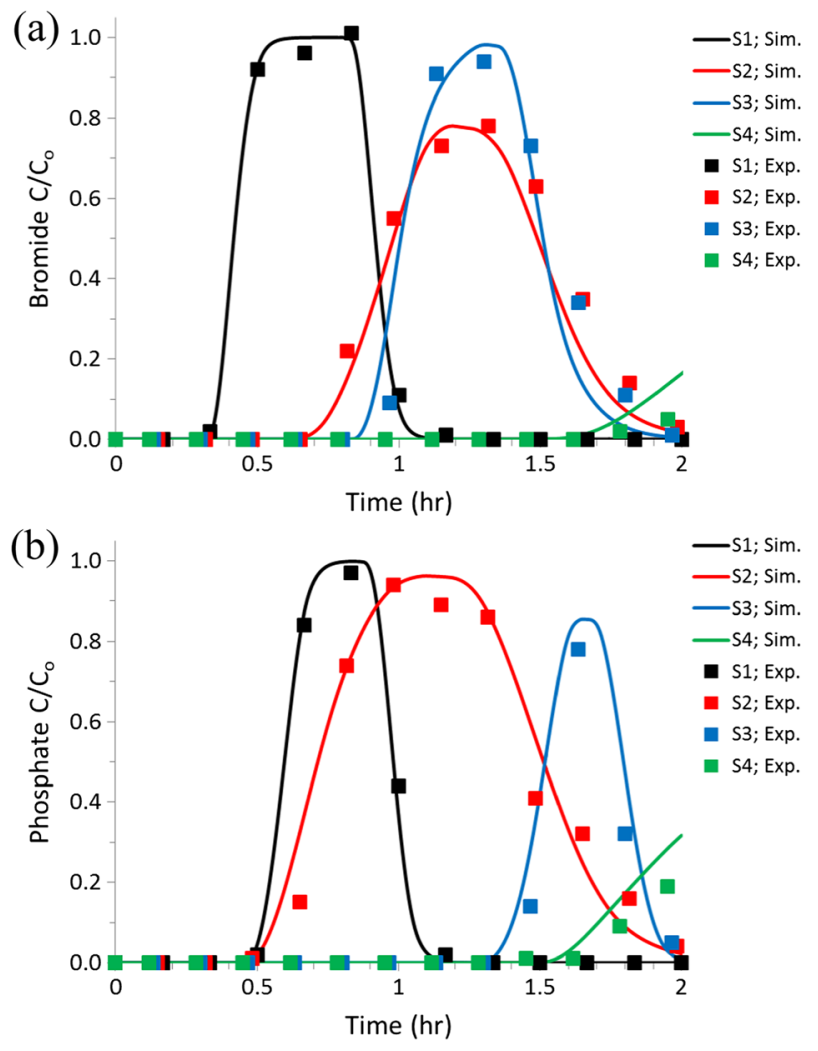

Fig. 12 Simulated and experimentally obtained (a) bromide concentrations for Exp. IIIa, and (b) phosphate concentrations for Exp. IIIb 


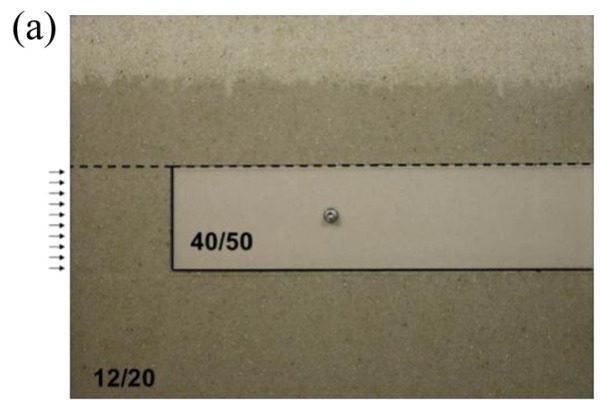

(b)

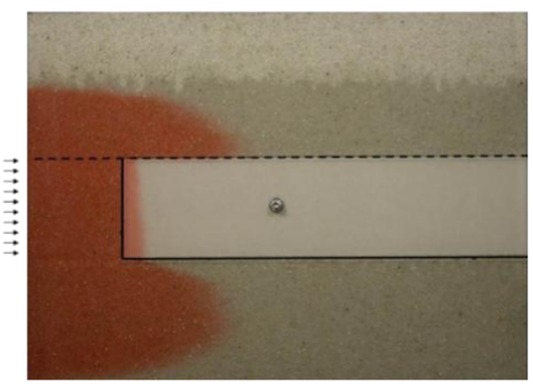

(c)
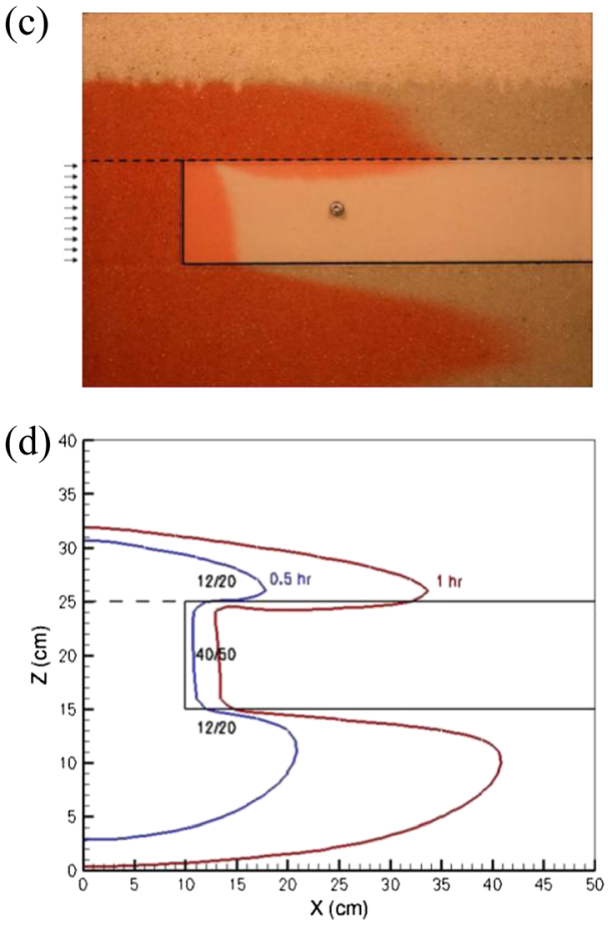

(e)

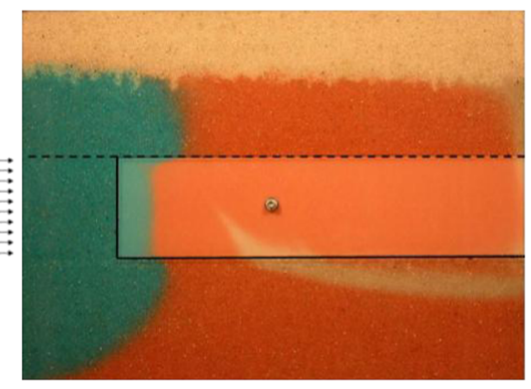

(f)

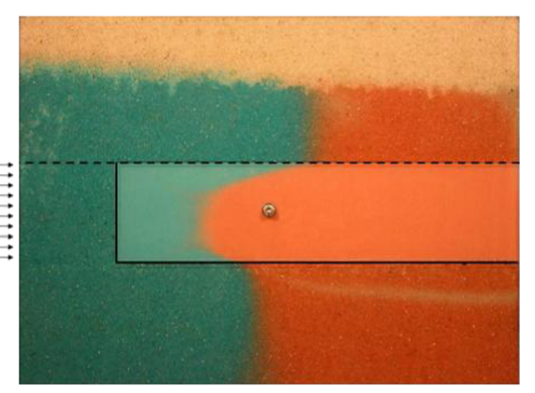

(g)

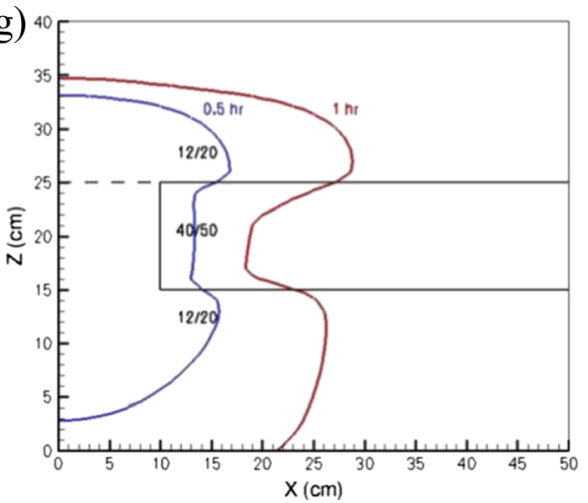

Fig. 13 Experiment IV: (a) configuration; tracer distribution at (b) $0.5 \mathrm{~h}$ and (c) $1 \mathrm{~h}$; (d) predicted tracer $\mathrm{C} / \mathrm{C}_{\mathrm{o}}=$

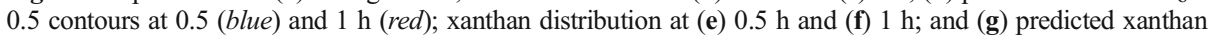
$\mathrm{C} / \mathrm{C}_{\mathrm{o}}=0.5$ contours at 0.5 (blue) and $1 \mathrm{~h}($ red $)$ 
In Exp. IIIa and IIIb, the fluids are injected into the lower-permeability sand (Fig. 10). The injection rate of $25 \mathrm{~mL} / \mathrm{min}$ corresponds to a boundary velocity of $8.33 \times 10^{-3} \mathrm{~cm} / \mathrm{s}$, which is smaller than the hydraulic conductivity $\left(8.04 \times 10^{-2} \mathrm{~cm} / \mathrm{s}\right)$ of the sand. However, the developed pressures in this sand are such that a considerable fraction on the injected red dye (Fig. 10b and c) migrates into the 12/20-mesh sand. During the polymer flood, mobility mitigation causes a reduction of the front velocity in the 12/20 sand on both sides of the lower-permeability layer and cross-flow into this layer from both is clearly visible after $1 \mathrm{~h}$ (Fig. 10f). The pressure differences in Fig. 11 support the visual cross-over observations in Fig. 10f. In this experiment, upon arrival of the STF, the pressure differences between $\mathrm{T} 1$ and $\mathrm{T} 3$ are larger than the differences between $\mathrm{T} 2$ and T4, indicating cross flow from the higher into the lower permeability sand. The numerical simulations of this configuration produce satisfactory results, including the prediction of the STF mounding observed in Fig. 10f, up to about $3 \mathrm{~cm}$. A comparison of the breakthrough behavior of bromide during the tracer and phosphate during the polymer flood, is shown in Fig. 12. The curves show the reduced movement in the higher permeability sand, and earlier arrival times in the 40/50-mesh sand. The breakthrough curve at port S2 for the polymer flood is much wider than for S1 and S3, reflecting cross flow from the higher permeability sand from both sides of the 40/50-mesh layer.

Exp. IV and Exp. V consider one modification each compared to Exp. III. In Exp. IV, the 40/50-mesh layer starts $10 \mathrm{~cm}$ from the inlet. In this configuration (Figs. 1d and 13a), the tracer
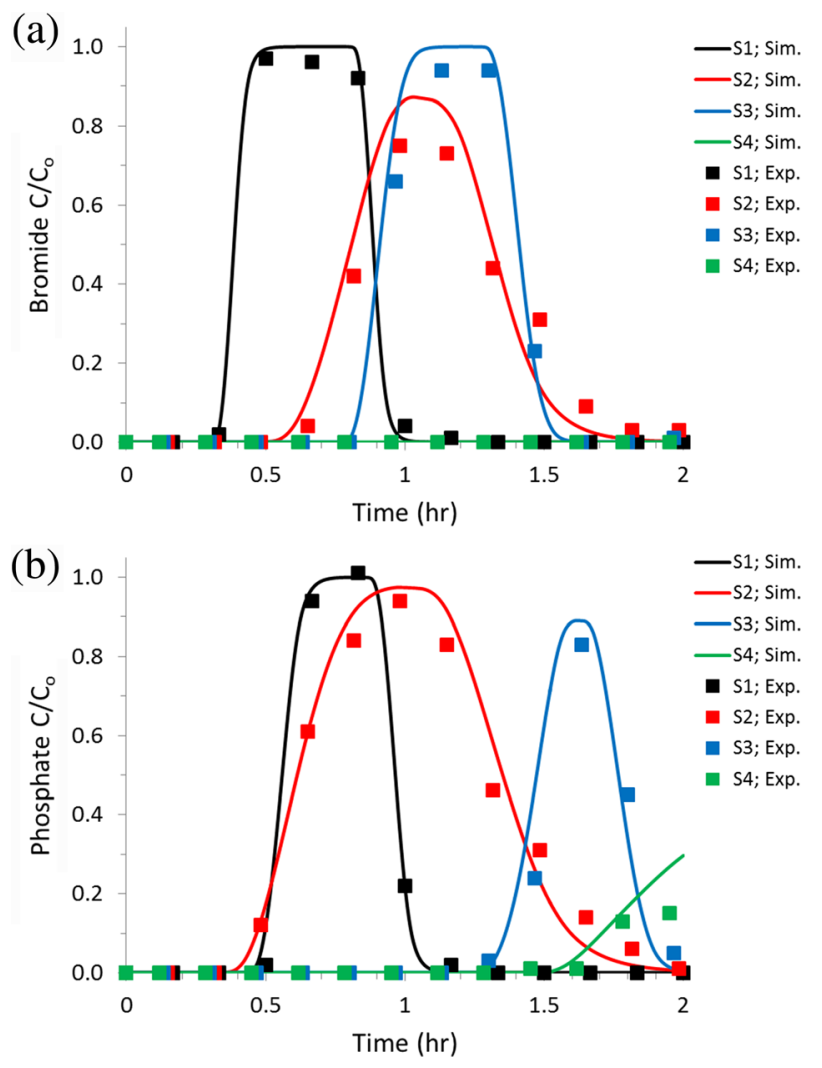

Fig. 14 Simulated and experimentally obtained (a) bromide concentrations for Exp. IVa, and (b) phosphate concentrations for Exp. IVb 
and polymer floods are not directly injected into the lower-permeability sand. This injection approach has also been used by Zhong et al. (2008; 2011) and Chokejaroenrat et al. (2013). In

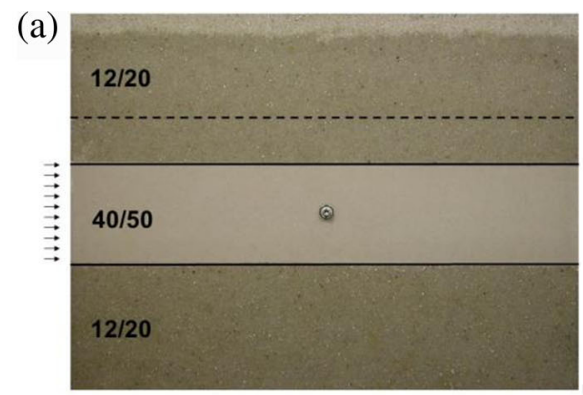

(b)

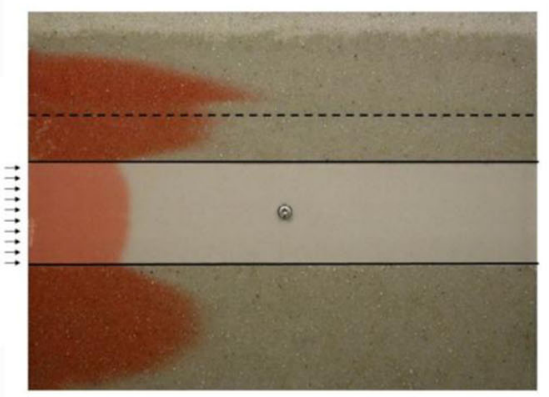

(c)

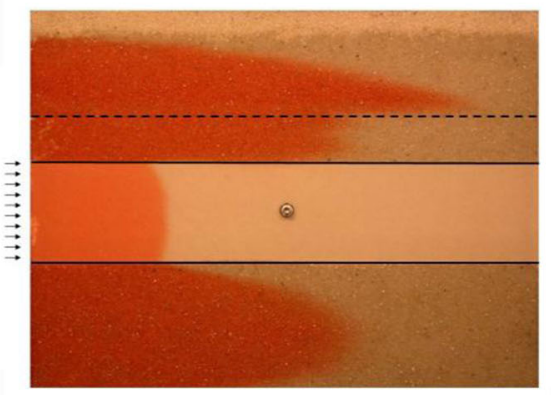

(d)

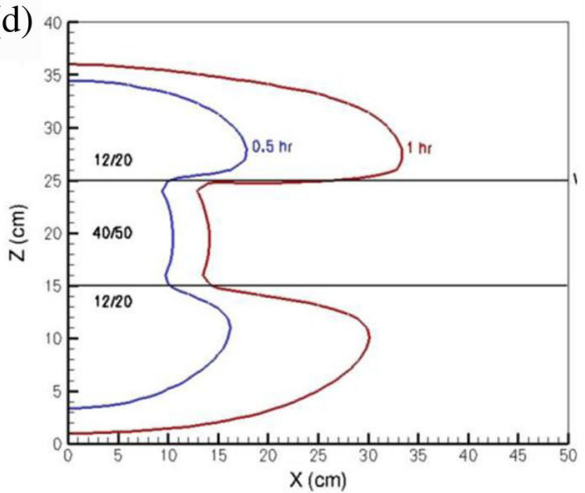

(e)

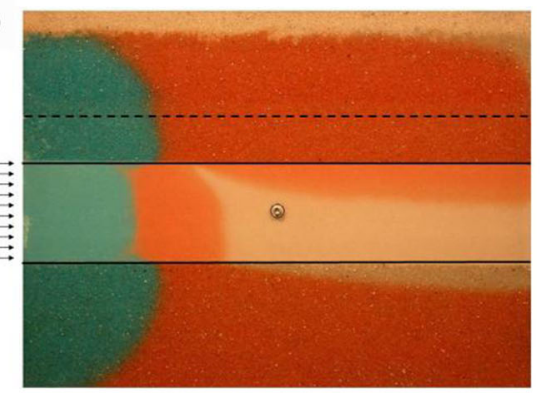

(f)

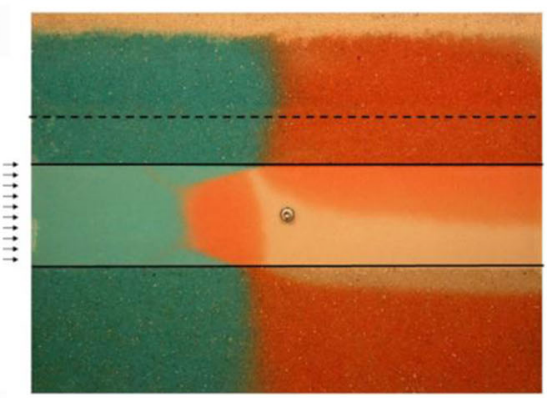

(g)

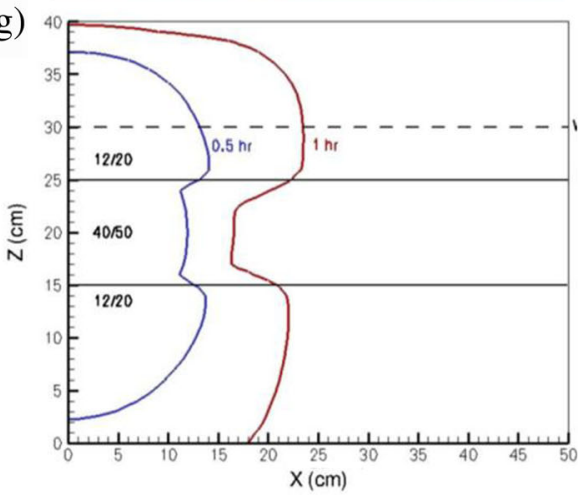

Fig. 15 Experiment V: (a) configuration; tracer distribution at (b) $0.5 \mathrm{~h}$ and (c) $1 \mathrm{~h}$; (d) predicted tracer $\mathrm{C} / \mathrm{C}_{\mathrm{o}}=$ 0.5 contours at 0.5 (blue) and $1 \mathrm{~h}(\mathrm{red})$; xanthan distribution at (e) $0.5 \mathrm{~h}$ and (f) $1 \mathrm{~h}$; and (g) predicted xanthan $\mathrm{C} / \mathrm{C}_{\mathrm{o}}=0.5$ contours at 0.5 (blue) and $1 \mathrm{~h}($ red $)$ 

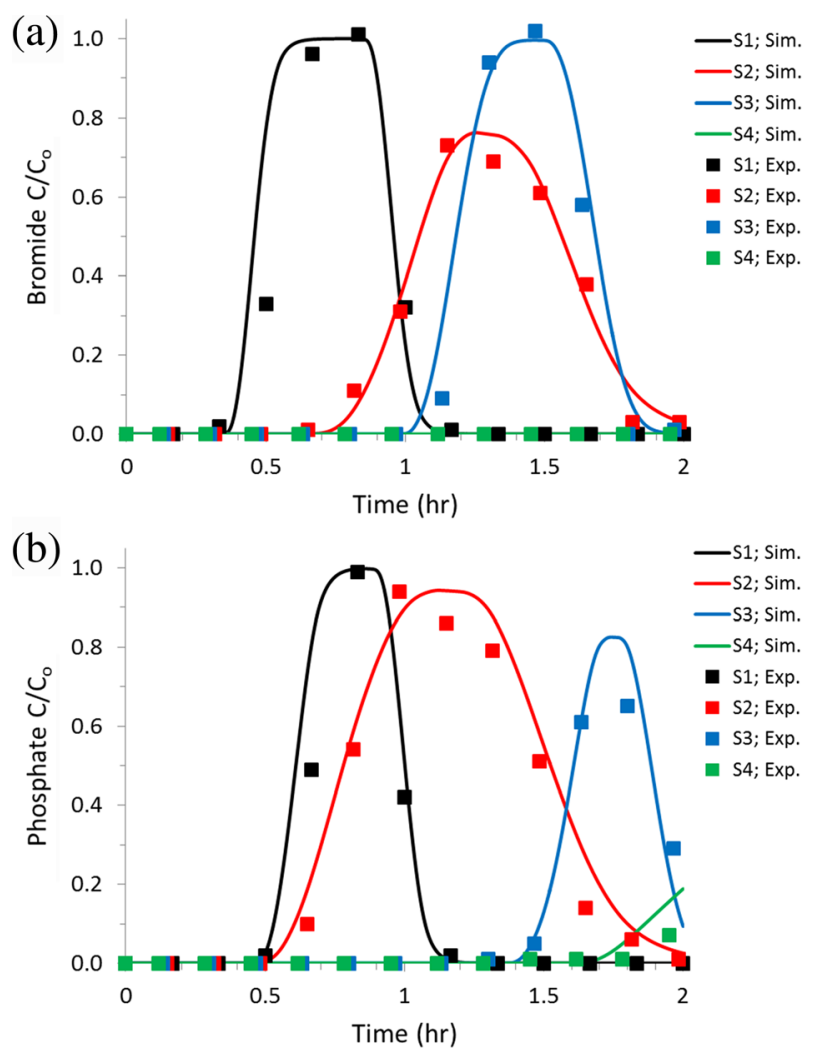

Fig. 16 Simulated and experimentally obtained (a) bromide concentrations for Exp. Va, and (b) phosphate concentrations for Exp. $\mathrm{Vb}$

Exp. V, the water table has been raised $5 \mathrm{~cm}$ (Figs. 1e and 15a) compared to Exp. III. The results of both Exp. IVb and Exp. Vb are quite similar to Exp. IIIb, both in terms of visualization (Figs. 13 and 15) and bromide/phosphate concentrations (Figs. 14 and 16), indicating the imposed changes were too small to cause considerable differences. Compared to Exp. III, the arrival times for all locations for Exp. Vb are slightly smaller at all locations, because a larger fraction of the injected STF is able to migrate into the extended saturated zone above the lower-permeability layer.

\section{Summary and Conclusions}

The use of shear thinning fluids (STFs) containing xanthan is a potential enhancement for emplacing a solute amendment near the water table and within the capillary fringe. As shown by a recent field application that did not employ STFs (i.e., the Hanford Site phosphate amendment example discussed in the introduction), only short term uranium concentration reductions were obtained, primarily due to insufficient contact time for the reactants as a result of large groundwater velocities through the treatment zone. Most research related to STF behavior has to date involved saturated and confined conditions. A series of flow cell 
experiments were conducted to investigate emplacement in variably saturated homogeneous and layered heterogeneous systems. Besides flow visualization, amendment (bromide and phosphate) concentrations and pressure data were obtained.

The results show that STFs considerably improved the distribution over the targeted interval by mitigating preferential flow through higher permeability zones compared to nopolymer injections. Using STFs led to enhanced delivery of remedial amendments to lower permeability zones and increased sweeping efficiencies. The amendment migrated with the STF without complications or retardation. The presence of an unsaturated zone did not result in unexpected STF behavior. Despite its high viscosity, the STF did not cause considerable mounding or preferential flow in the unsaturated zone. Cross flow between layers could be interpreted as the main mechanism to transport STFs into lower permeability layers based on the observed pressure gradient and concentration data in layers of differing hydraulic conductivity.

The STOMP simulator, accounting for the measured STF viscosity - shear rate relation, was able to predict the experimentally observed fluid displacement, fluid pressures, and dissolved amendment concentrations well. The satisfactory match between prediction and experimental results indicates that for the investigated flow cell systems with clean laboratory sands, advanced modeling features to describe subsurface xanthan behavior, such as sorption, mechanical filtration and permeability reduction (Silva et al. 2013), or explicit viscosity computation using the Brinkman equation (Chokejaroenrat et al. 2013) were not important.

The experiments and numerical simulations in this contribution show that the enhanced remedial amendment delivery approach using STFs may be applied to aquifer remediation sites where the emplacement of remedial amendments such as nutrients and reactive reagents to lower permeability zones are required. However, the work described in this paper should be regarded as an initial effort to improve the understanding of STF behavior for near-water table injection scenarios. Additional experiments are needed to investigate the effects of larger permeability ratios, more complex packing geometries, and actual site sediments on STF and amendment distribution. Experiments are also needed to evaluate contaminant sequestration or degradation after emplacement of the amendment with the STF.

Acknowledgments Funding for this study was provided by CH2M Hill Plateau Remediation Company. PNNL is operated by the Battelle Memorial Institute for the Department of Energy (DOE) under Contract DE-AC0676RLO 1830. The intermediate-scale experiments were performed in the Environmental Molecular Sciences Laboratory (EMSL), a national scientific user facility sponsored by the DOE's Office of Biological and Environmental Research and located at PNNL. Scientists interested in conducting experimental work in the EMSL are encouraged to contact M. Oostrom (mart.oostrom@pnnl.gov).

\section{References}

Brinkman H (1949) A calculation of the viscous force exerted by a flowing fluid on a dense swarm of particles. Appl Sci Res 1:27-34

Chapman SW, Parker BL (2005) Plume persistence due to aquitard back diffusion following dense nonaqueous phase liquid removal or isolation. Water Resour Res 41:W12411

Chokejaroenrat C, Kananizadeh N, Sakulthaew C, Comfort S, Li Y (2013) Improving the sweeping efficiency of permanganate into low permeable zones to treat TCE: experimental results and model development. Environ Sci Technol 47:13031-13038

Chokejaroenrat C, Comfort S, Sakulthaew C, Dvorak B (2014) Improving the treatment of non-aqueous phase TCE in low permeability zones with permanganate. J Hazard Mater 268:177-184 
Comba S, Sethi R (2009) Stabilization of highly concentrated suspensions of iron nanoparticles using shearthinning gels of xanthan gum. Water Res 43:3717-3726

Comba S, Dalmazzo D, Santagata E, Sethi R (2011) Rheological characterization of xanthan suspensions of nano scale iron for injection in porous media. J Hazard Mater 185:598-605

Cross MM (1965) Rheology of non-Newtonian fluids. A new flow equation for pseudoplastic systems. J Colloid Sci 20:417-437

Delshad M, Pope GA, Sephernoori K (1996) A compositional simulator for modeling surfactant enhanced aquifer remediation. 1. Formulation. J Contam Hydrol 23:303-327

Lopez X, Valvatne PH, Blunt MJ (2003) Predictive network modeling of single-phase non-Newtonian flow in porous media. J Colloid Interface Sci 263:256-265

Martel KE, Martel R, Lefebvre RJ, Gelinas PJ (1998) Laboratory study of polymer solutions used for mobility control during in situ NAPL recovery. Groundw Monit Remediat 18:103-113

Meter JW, Bird RB (1964) Tube flow of non-Newtonian polymer solutions. Parts I and II - Laminar flow and rheological models. AICHE J 10:1143-1150

Mualem Y (1976) A new model predicting the hydraulic conductivity. Geoderma 65:81-92

Oostrom M, Hofstee C, Dane JH, Lenhard RJ (1998) Single-source gamma radiation for improved calibration and measurements in porous media systems. Soil Sci 163:646-656

Oostrom M, White MD, Brusseau ML (2001) Theoretical estimation of interfacial areas of entrapped and free nonwetting fluids in porous media. Adv Water Resour 24:887-898

Oostrom M, Wietsma TW, Covert MA, Vermeul VR (2007) Zero-valent iron emplacement in permeable porous media using polymer additions. Groundw Monit Remediat 27:122-130

Patankar SV (1980) Numerical heat transfer and fluid flow. Hemisphere Publishing Corporation, Washington

Robert T, Martel R, Conrad SH, Lefevre R, Gabriel U (2006) Visualization of TCE recovery mechanisms using surfactant-polymer solutions in a two-dimensional heterogeneous sand model. J Contam Hydrol 86:3-31

Schroth MH, Ahearn SJ, Selker JS, Istok JD (1996) Characterization of Miller-similar silica sands for laboratory hydrologic studies. Soil Sci Soc Am J 60:1331-1339

Schroth MH, Oostrom M, Wietsma TW, Istok JD (2001) In situ oxidation of trichloroethene by permanganate: effects on porous medium hydraulic properties. J Contam Hydrol 50:79-98

Shi Z, Liu C, Zachara J, Wang Z, Deng B (2009) Inhibition effect of secondary phosphate mineral precipitation on uranium release from contaminated sediments. Environ Sci Technol 43:8344-8349

Silva JAK, Smith M, Munakata-Marr J, McCray JE (2012) The effect of system variables on in situ sweepefficiency improvements via viscosity modification. J Contam Hydrol 136:117-130

Silva JAK, Liberatore M, McCray JE (2013) Characterization of bulk fluid and transport properties for simulating polymer-improved aquifer remediation. J Environ Eng 139:149-159

Smith M, Silva JAK, Munakata-Marr J, McCray JE (2008) Compatibility of polymers and chemical oxidants for enhanced groundwater remediation. Environ Sci Technol 42:9296-9301

Tiraferri A, Sethi R (2009) Enhanced transport of zero valent iron nanoparticles in saturated porous media by guar gum. J Nanoparticle Res 11:635-645

Tiraferri A, Chen KL, Sethi R, Elimelech M (2008) Reduced aggregation and sedimentation of zero-valent iron nanopraticles in the presence of guar gum. J Colloid Interface Sci 324:71-79

Tosco T, Sethi R (2010) Transport of non-Newtonian suspensions of highly concentrated micro-and nanoscale iron particles in porous media: a modeling approach. Environ Sci Technol 44(23):9062-9068

Truex MJ, Vermeul VR, Mendoza DP, Fritz BG, Mackley RD, Oostrom M, Wietsma TW, Macbeth TW (2011) Injection of zero valent iron into an unconfined aquifer using shear-thinning fluids. Groundw Monitor Remediat 31:50-58

Truex MJ, Vermeul VR, Adamson DT, Oostrom M, Zhong L, Mackley RD, Fritz BG, Horner JA, Johnson TC, Thomle JN, Newcomer DR, Johnson CD, Rysz M, Wietsma T, Newell CJ (2014) Field test of enhanced remedial amendment delivery using a shear-thinning fluid. Submitted to Groundwater Monitoring and Remediation

van Genuchten M (1980) A closed-form equation for predicting the hydraulic conductivity of unsaturated soil. Soil Sci Soc Am J 44:892-898

Vecchia ED, Luna M, Sethi R (2009) Transport in porous media of highly concentration iron micro- and nanoparticles in the presence of xanthan gum. Environ Sci Technol 43:8942-8947

Vermeul VR, Bjornstad BN, Fritz BG, Fruchter JS, Mackley RD, Newcomer DR, Mendoza DP, Rockhold ML, Wellman DM, Williams MD (2009) 300 Area Uranium Stabilization Through Polyphosphate Injection: Final Report. PNNL-18529, Pacific Northwest National Laboratory, Richland, WA

Wellman DM, Glovack JN, Parker K, Richards EL, Pierce EM (2008) Sequestration and retention of uranium(VI) in the presence of hydroxylapatite under dynamic geochemical conditions. Environ Chem 5:40-50

White MD, Oostrom M (2006) STOMP: Subsurface Transport Over Multiple Phases, Version 4.0. User's Guide. PNNL-15782. Pacific Northwest National Laboratory, Richland, WA 
Wietsma TW, Oostrom M, Covert MA, Queen TE, Fayer MJ (2009) An automated tool for three types of saturated hydraulic conductivity laboratory measurements. Soil Sci Soc Am J 73:466-470

Xue D, Sethi R (2012) Viscoelastic gels of guar and xanthan gum mixtures provide long-term stabilization of iron micro- and nanoparticles. J Nanoparticle Res 14:1239. doi:10.1007/s11051-012-1239-0

Zhong L, Oostrom M, Wietsma TW, Covert MA (2008) Enhanced remedial amendment delivery through fluid viscosity modifications: experiments and numerical simulations. J Contam Hydrol 101:29-41

Zhong L, Szecsody JE, Oostrom M, Truex MJ, Shen X, Li X (2011) Enhanced remedial amendment delivery to subsurface using shear thinning fluid and aqueous foam. J Hazard Mater 191:249-257

Zhong L, Oostrom M, Truex MJ, Vermeul VR, Szecsody JE (2013) Rheological behavior of xanthan gum solution related to shear thinning fluid delivery for subsurface remediation. J Hazard Mater 244-245:160-170 